NBER WORKING PAPER SERIES

\title{
PATENTS IN THE UNIVERSITY: \\ PRIMING THE PUMP AND CROWDING OUT
}

\author{
Suzanne Scotchmer \\ Working Paper 19252 \\ http://www.nber.org/papers/w19252
NATIONAL BUREAU OF ECONOMIC RESEARCH
1050 Massachusetts Avenue
Cambridge, MA 02138
July 2013

I thank Nisvan Erkal and Hugo Hopenhayn for motivating discussions, and Pierre Regibeau and Mark Schankerman for queries that much improved the paper. I thank the Toulouse Network on Information Technology, NSF Grant 0830186, and the Sloan Foundation for funding. I thank the Toulouse School of Economics for hospitality during the preparation of this paper. The views expressed herein are those of the author and do not necessarily reflect the views of the National Bureau of Economic Research.

NBER working papers are circulated for discussion and comment purposes. They have not been peerreviewed or been subject to the review by the NBER Board of Directors that accompanies official NBER publications.

(C) 2013 by Suzanne Scotchmer. All rights reserved. Short sections of text, not to exceed two paragraphs, may be quoted without explicit permission provided that full credit, including $\odot$ notice, is given to the source. 
Patents in the University: Priming the Pump and Crowding Out

Suzanne Scotchmer

NBER Working Paper No. 19252

July 2013

JEL No. K0,L00,O34

\begin{abstract}
$\underline{\text { ABSTRACT }}$
The Bayh-Dole Act allows universities to exploit patents on their federally sponsored research. University laboratories therefore have two sources of funds: direct grants from sponsors and income from licensing. Tax credits for private R\&D also contribute, because they increase the profitability of licensing. Because Bayh-Dole profits are a source of funds, the question arises how subsidies and Bayh-Dole profits fit together. I show that subsidies to the university can either "prime the pump" for spending out of Bayh-Dole funds, or can crowd it out. Because of crowding out, if the sponsor wants to increase university spending beyond the university's own target, it will end up funding the entire research bill, just as if there were no profit opportunities under the Bayh-Dole Act. A subsidy system that requires university matching can mitigate this problem.
\end{abstract}

Suzanne Scotchmer

Department of Economics

Evans Hall

University of California

Berkeley, CA 94720-3880

and NBER

scotch@berkeley.edu 


\section{Introduction}

The Bayh-Dole Act of 1980 authorized universities to own and license the patents that result from federally sponsored research. The primary hope was that universities would try to make their work useful in the economy. However, a secondary hope might have been that it would relieve financial pressure on universities' research budgets, and ultimately on federal sponsors. The question in this paper is whether that could work.

I propose a concrete model of the research process that allows me to assess (1) the role of research subsidies when universities earn profits under the Bayh-Dole Act, and (2) the economic rationale, if any, for the Act. One of the key questions is whether research subsidies actually increase research expenditures, or whether they simply crowd out BayhDole profits.

To address these questions, I need a model of research that distinguishes the type of research done in universities from the more applied research required to create a marketable innovation. A widely held view is that the proper distinction has something to do with the level of abstraction, or "basicness." I propose that there are two distinct research activities: the activity of turning up abstractions (ideas, understood as investment opportunities), and the activity of turning the investment opportunities into innovations. I thus follow O'Donoghue, Scotchmer and Thisse (1998), Scotchmer (1999), Erkal and Scotchmer (2007, 2009) in distinguishing between investment opportunities, which are scarce, and the investments or innovations themselves.

In this stylization, the costs borne by the university and costs borne by firms have different natures. The university bears a flow cost of doing research, and the flow cost turns up a series of random investment opportunities (abstract ideas). A higher flow cost of R\&D leads to a higher flow of ideas. In contrast, the R\&D costs borne by firms are targeted to the implementation of particular investment ideas.

The Bayh-Dole Act only has force if the knowledge turned up in universities is patentable. However, a tension at the heart of this paper is that ideas or abstractions are generally not patentable. 
The patent-ineligibility of abstract ideas was affirmed in 2008 by the U.S. Supreme Court in the informative case, Bilski. Bilski's patent application was on a business method that allows home owners to smooth their heating bills and thus hedge against the risk of bad weather or fluctuations in price. The application had been rejected by the Federal Circuit as not satisfying their machine-or-transformation test. The Supreme Court held that the machine-or-transformation test is not dispositive, but, citing their previous opinions, still rejected the patent application as an attempt to patent an abstract idea.

In fact, much of the knowledge turned up in universities would not pass the Federal Circuit's machine-or-transformation test for patentability, and could easily be categorized as "abstractions." If so, the Bayh-Dole Act has no effect. Perhaps because of this, university licensing offices have been much less lucrative than was hoped. Licensing revenue provides less than $5 \%$ of universities' research budgets (see Thursby and Thursby, 2003, and Mowery et al, 2004), and there are only a handful of profitable licensing offices. Most are deeply in the red.

Part of my inquiry is whether the Bayh-dole Act was a good idea, and if so, whether patent law should be more accommodating of "abstractions." That is, should the ideas produced in universities be patentable? I take this as a policy question.

I make a distinction between intellectual property rights on the "idea" and intellectual property rights on the innovation that results from it. Patent law is friendlier to patents on commercial products than to patents on ideas or abstractions, as we have just seen. If the idea is protected, and becomes a profitable innovation, the commercial firm that develops the idea does not need an additional patent. However, if the idea cannot be patented, a patent on the commercial innovation is necessary. Without it, a profit-motivated firm would not invest.

If the idea is protected, then it can be auctioned exclusively to a commercializing firm, and the university will collect the profit. If the idea is not protected, the university cannot auction the exclusive use of it. Because university researchers publish, the idea will enter the public domain, and there may be a patent race for the innovation. The patent race will 
dissipate profit. Even though the winner of the patent race will have a protected innovation, the firms in the patent race make zero profit in expectation, and the university gets nothing. Thus, the Bayh-Dole Act will only generate profit for the university if ideas are patentable.

Assuming then that ideas are patentable, one of my main questions is whether the Bayh-Dole Act relieves the pressure on sponsors to subsidize research. This is relevant if the university can find ways to "tax" the Bayh-Dole profit for other purposes. If so, the subsidies might do nothing more than crowd out the use of Bayh-Dole funds. To increase the university's research spending, sponsors would have to pay the entire research bill, so that further crowding out is impossible. Crowding out puts the sponsors in the same funding position as if there were no Bayh-Dole Act.

Whether there is crowding out depends both on the university's preferences and on its flexibility in revising the internal levy in response to subsidies. If the university's levy on Bayh-Dole profits is fixed when the subsidy is announced, the subsidy "primes the pump" and increases the university's spending on research. In contrast, if the levy can be adjusted to the subsidy, then the subsidy can "crowd out" the Bayh-Dole profits, without increasing the research spending at all.

A direct instrument to limit the problem of crowding out is to provide subsidies on a matching basis. The sponsor can simply require that the university provides a specified share of the research budget. I investigate whether the sponsor can then achieve the efficient level of R\&D spending while also making sure that Bayh-Dole profits are returned to the research process.

Crowding out seems to be a perverse consequence of the Bayh-Dole Act that has not previously been studied, either theoretically or empirically. The empirical studies fall into several broad approaches, those that investigate whether the Bayh-Dole Act changed the size or quality of university patent portfolios (Henderson, et al, 1998, Mowery and Ziedonis, 2002, Sampat, Mowery and Ziedonis, 2003), one that investigates whether the Bayh-Dole Act changed the type of research that is funded (Rafferty, 2008), and several that focus on the incentives of scientists (Azoulay et al, 2009, Thursby and Thursby, 2011, Lach and 
Schankerman, 2008). The theoretical studies are mostly concerned with the incentives of scientists (Thursby et al, 2007, Gans and Murray, 2011, Aghion et al, 2008, BanalEstañol and Macho-Stadler, 2010, Jensen, et al, 2010). Overall, the empirical studies do not support the notion that basic research declined with the enactment of the Bayh-Dole Act. However, this does not mean that scientists are immune to incentives. Lach and Schankerman (2008) discover that universities earn higher licensing revenue when they pay higher royalty shares to their scientists. The surprise is that these incentives may lead to more scientific publication rather than less. Azoulay et al (2009) discover that patenting and academic publication go hand in hand.

This paper takes a different approach, in that it focusses on the incentives of the university rather than of the scientists. The university may view the research division as a convenient source of revenue, and may want to tax the profits. It is the university's desire to tax the researchers that can lead to crowding out.

The profit-sharing within the university is generally hard to figure out. Lach and Schankerman (2008) shed some light on the question by investigating how much profit is given to researchers. The portion assigned to the researcher varies considerably among universities, between $21 \%$ and $65 \%$. When the rate is nonlinear (decreasing with income) the spread is wider. Admittedly, these data can be interpreted in different ways. It seems natural to interpret the researcher's portion as part of his or her salary in expectation, but that does not resolve it. The salary can be understood as an obligation of the general fund. What is hard to figure out is how much of the profit comes back to the research division to funds laboratories. In any case, the data show that profit sharing is an essential part of the Bayh-Dole ecology.

Section 2 presents a model of idea generation and development. Section 3 characterizes the optimal innovation policy when ideas are protectable, and the university's tax on profit from commercialization is set before the subsidies are chosen. Section 4 addresses the reverse timing, where the subsidy is set before the university's tax. In section 5 , I investigate the improvement when subsidies require some kind of matching. Section 6 explains why it 
might be efficient to allow patenting of ideas instead of (only) their commercial reifications, despite crowding out. That is, the Bayh-Dole Act is not as misguided as some commentators believe. In section 6 I comment on notions of basic research, and how this model relates to them.

\section{A model}

There are two types of research: university research that produces a stream of ideas that could become innovations, and commercial research that develops ideas into innovations. An idea is represented by a pair of parameters $(v, c)$, where $v$ measures its per period social value and $c$ measures the cost that must be invested. ${ }^{1}$ Following Scotchmer (1999), each idea is drawn from a distribution $F$, with density $f$, where $f(v, c)$ is the density. Figure 1 shows a space of ideas $(v, c)$, with cost on the vertical axis and per-period social value $v$ on the horizontal axis. The value $v$ is the per-period social value if the good is supplied competitively, with total discounted social value $v / r$.

In this paper I take as a premise that the development of ideas is left to the private sector. However, if ideas were perfectly observable to public sponsors, or if sponsors could elicit the parameters $(v, c)$ of an idea with some cleverly designed mechanism, then patents should be avoided at that stage as well. The better mechanism would be to elicit the information, decide which ideas $(v, c)$ to invest in, and then pay the cost of investment from efficiently collected public funds. However, when ideas are private, there is no obvious mechanism to elicit the information $(v, c)$. My (1999) paper promotes the idea that patents can only be optimal if the values of ideas are not observable to sponsors. That is also the point of view taken here. ${ }^{2}$

I first discuss the model of developing ideas, and then discuss the ideas process in more

\footnotetext{
${ }^{1}$ The focus in this paper is on the idea generation process, not on the more standard problem of how to elicit R\&D investments when the investment opportunity is already known. Thus I have chosen a very simply cost structure for the innovation. One could obviously change the strcuture to involve moral hazard or other problems which would have implications for how to structure the reward.

${ }^{2}$ This condition can be understood as not very restrictive. If two or more firms can observe the value of an idea, then they have perfectly correlated information, and there are zero-cost mechanisms to make them announce it.
} 


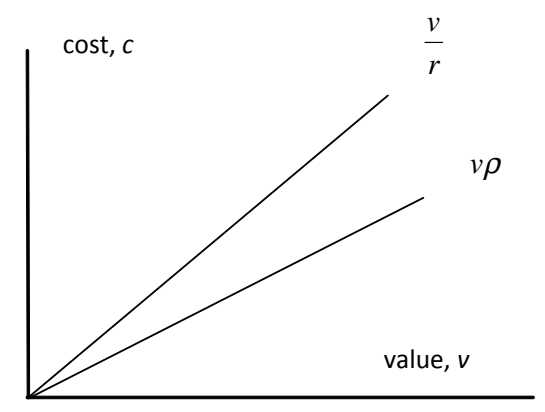

Figure 1: Policy toward commercializations, where $\rho=\frac{\pi T}{1-\tau}$

detail. For the main points of this paper, the details in section 2.1 are mostly unnecessary. What is necessary is to realize that there are policy instruments summarized in a parameter $\rho$ such that profit is increasing in $\rho$, and there is an optimal (finite) reward structure, $\rho^{*}$. The parameter $\rho$ reflects the patent life and tax credits.

One reason to be explicit about the model of development incentives is to emphasize that tax credits might be an optimal complement to the patent policy. Tax credits will encourage investment in ideas that would otherwise be marginal, while creating windfall profits on ideas that would be profitable anyway. But that is also true of the patent life. Increasing the patent life will encourage investments at the margin, while creating windfall profits for already profitable investments. As a policy instrument for generating profit, the patent life has an obvious defect - it creates deadweight loss. Unless there is some administrative loss (which I assume below), tax credits are just a transfer from taxpayers to innovators. Unless the administrative loss is large, tax credits are attractive.

\subsection{Developing ideas}

The two policy instruments at the development stage are a patent life $T$, which is interpreted as discounted, ${ }^{3}$ and a tax credit $\tau \in[0,1]$, which allows the government to share the cost of commercialization. If $\pi$ is the percentage of consumer value that the proprietor collects

\footnotetext{
${ }^{3}$ If $\hat{T}$ is the patent life measured in undiscounted years, then $T=\int_{0}^{\hat{T}} e^{-r t} d t$ is the dicounted patent life. Its minimum is 0 , achieved when the undiscounted patent life is 0 , and its maximum is $1 / r$, achieved with the undicounted patent life is infinite.
} 
as profit in each time period, an idea $(v, c)$ is profitable when

$$
\begin{aligned}
\pi T v-(1-\tau) c & \geq 0 \\
\frac{\pi T}{(1-\tau)} v-c & \geq 0
\end{aligned}
$$

Let $\rho$ represent the profitability of the private incentive system, defined as

$$
\rho:=\frac{\pi T}{(1-\tau)}
$$

where $(T, \tau)$ are the policy variables. In figure 1 , only the ideas $(v, c)$ under the line $\rho v$ will be developed.

If the profitability satisfies $\rho=1 / r$, then all ideas with cost below the $v / r$ threshold in figure 1 will be developed. This would be optimal if it were costless to raise funds through either a patent life or a tax subsidy. However, such high rewards are not optimal if the patent life imposes deadweight loss or if there are inefficiencies due to the tax subsidy. The deadweight loss due to the patent can be mitigated, while preserving the profitability $\rho$, by shortening the patent life and giving a larger tax credit.

However tax credits may also be inefficient. I shall assume that for every project that is subsidized at rate $\tau$, there is a waste $K(\tau)$, where the function $K$ is convex, increasing, and $K(0)=K^{\prime}(0)=0$. I assume that the waste is not a pure transfer, but rather that at least part of it is social waste due to inefficient actions.

For each level of profitability $\rho$, there is an optimal combination of patent life and tax subidy $(T(\rho), \tau(\rho))$ which maximize the expected consumer value of commercializing the ideas below the line in figure 1 defined by $\rho v$. We shall let $\epsilon(\rho)$ represent the expected social value of these commercializations:

$$
\begin{aligned}
\epsilon(\rho) & =\max _{\left(T, \tau \mid \rho=\frac{\pi T}{(1-\tau)}\right)} \int_{0}^{\infty} \int_{0}^{\rho v}[v / r-d T v-c-K(\tau)] f(c, v) d c d v \\
& =\int_{0}^{\infty} \int_{0}^{\rho v}[v / r-d T(\rho) v-c-K(\tau(\rho))] f(c, v) d c d v
\end{aligned}
$$

where $d$ is the fraction of social value that is lost as deadweight loss in each period. 
The optimal $(T(\rho), \tau(\rho))$ have the property that an increase in patent life would increase deadweight loss by the same amount as the efficiency loss in boosting the tax subsidy enough to achieve the same increase in $\rho$. The optimal patent life is not zero, and if $K^{\prime}(0)=0$, the optimal tax credit $\tau$ is also positive.

Let $\rho^{*}$ be the reward that maximizes $\epsilon(\rho)$. This optimum has the property illuminated by Nordhaus (1969) that while an increase in $\rho$ would increase commercializations, it also creates windfall profit on inframarginal innovations through either a longer patent life or more tax subsidies, and these create social costs that just offset the social value of supporting more commercializations.

Assuming that ideas are commercialized whenever profitable, write $\Pi(\rho)$ for their perperiod profitability on average, taking account of the fact that not all are commercialized. The expected profit of a random idea is

$$
\Pi(\rho) \equiv \int_{\{(v, c): c \leq \rho v\}}[\pi v T(\rho)-(1-\tau) c] d F(c, v)
$$

The functions $\Pi$ is increasing. A higher value of $\rho$ makes each idea more profitable, and also increases the fraction of ideas that will be commercialized.

\subsection{The ideas process}

I stressed in the introduction that the nature of costs is different for commercializations than for generating ideas. The research costs of commercialization are targeted to the idea, namely, the $c$ in $(v, c)$. In contrast, the university invests a flow of funds to turn up a random sequence of abstract ideas (investment opportunities). Ideas are random in both their timing, and in their value and costs $(v, c)$.

More particularly, I assume that if the university invests a flow of funds $x$, ideas for commercial investment emerge at a Poisson rate $\theta(x)$, where $\theta$ is an increasing function. Because each idea yields expected social value $\epsilon(\rho)$, the flow of social value created is $\theta(x) \epsilon(\rho) d t$ and the flow of costs is $x d t$. Thus, consumer welfare can be written as the 
following function of $(x, \rho)$ :

$$
W(x, \rho) \equiv \frac{1}{r}[\epsilon(\rho) \theta(x)-x]
$$

Let $\left(x^{*}, \rho^{*}\right)$ be the maximizers of (3). Thus, $\rho^{*}$ is the maximizer of $\epsilon(\rho)$, and $x^{*}$ is the consumer-optimal level of spending on idea generation. It satisfies ${ }^{4}$

$$
\epsilon\left(\rho^{*}\right) \theta^{\prime}\left(x^{*}\right)-1=0
$$

The optimum cannot be achieved directly because $R \& D$ spending is not directly under the control of the social planner. In the next three section, the planner is assumed to have different tools for encouraging efficient investment. $\rho$ is the profitability of developing ideas, under the control of both a tax credit and a patent life. I will understand that the patent life and tax subsidy $(T(\rho), \tau(\rho))$ are chosen as the optimal way to achieve $\rho$. For generating ideas, I will consider two different policy instruments: direct subsidies (sections 3 and 4) and matching subsidies (section 5).

When ideas are patentable, both the direct subsidy to the university and the tax credit $\tau$ to developers are valuable to the university. High tax credits will be passed through to the university as high licensing fees.

I will use the term Bayh-Dole profits for the net revenues that arise from the university's development activities, namely $\Pi(\rho) \theta(x)$, where $\rho$ is the reward parameter for developed ideas, and $x$ is the rate of $\mathrm{R} \& \mathrm{D}$ spending in the university.

\section{Subsidies that Prime the Pump}

Let $b$ represent the university's contribution to research expenditures, funded from BayhDole profits, and let $s$ represent the subsidy. Total research spending is $s+b$. I assume that the research division of the university must balance its budget. After paying any levy imposed by the university, it must still cover its own R\&D expenditures from the sum of

\footnotetext{
${ }^{4}$ The optimal level of research is lower if there is a cost to raising public funds. If the cost of raising one dollar for the direct subsidy were $k>1$, then the first order condition for the optimal level of funding $x^{k}$ would satisfy $\epsilon\left(\rho^{*}\right) \theta^{\prime}\left(x^{k}\right)=k>1$, assuming the marginal research dollar is provided through subsidy.
} 
Bayh-Dole profits and subsidies. The budget constraint can be written as follows, where $t$ is a levy imposed by the university for its general fund:

$$
(1-t) \Pi(\rho) \theta(b+s)-b=0
$$

This formulation takes seriously that Bayh-Dole profits are a tempting target for cashstrapped universities, and there is no reason the funds need to be returned to the research process. I assume that $t \geq 0$. The research division cannot be a net drain on the rest of the university.

Write $\beta(s, t)$ for the university's maximum feasible expenditure on research, namely, the maximum value of $b$ that satisfies the research division's budget constraint (5). For $t=0, \beta(s, 0)$ is the entire Bayh-Dole profit. If there is a levy, the Bayh-Dole profit is $\Pi(\rho) \theta(\beta(s, t)+s)$, which is divided between the general fund and the research enterprise, according to the levy.

The function $\beta$ also depends on $\rho$, but I will assume that $\rho$ is optimally chosen, and avoid the more complicated notation. The following assumption implies that (5) has a unique solution except when $s=0$, and then we take $\beta(0, t)$ to be the positive solution rather than zero.

Assumption 1: $\theta$ is a strictly concave, increasing function such that $\theta(0)=0$ and

$$
\begin{aligned}
& \lim _{x \rightarrow 0} \theta^{\prime}(x) \rightarrow \infty \\
& \lim _{x \rightarrow \infty} \frac{\theta(x)}{x}=0
\end{aligned}
$$

Assumption 1 ensures that $\theta(b)$ is larger than $b$ for small $b$ and smaller than $b$ for large $b$. Thus, $(1-t) \Pi(\rho) \theta(b+s)$ crosses the diagonal in figure 2 . The research division spends a budget of $(1-t) \Pi(\rho) \theta(b+s)+s$. Assumption 1 ensures that all the objective functions considered in this paper are strictly concave.

The university chooses the levy $t$. For the moment I will assume that this choice is the primitive reflection of the university's preferences. In the next section I will assume that the university's levy is an endogenous consequence of more primitive preferences. The 


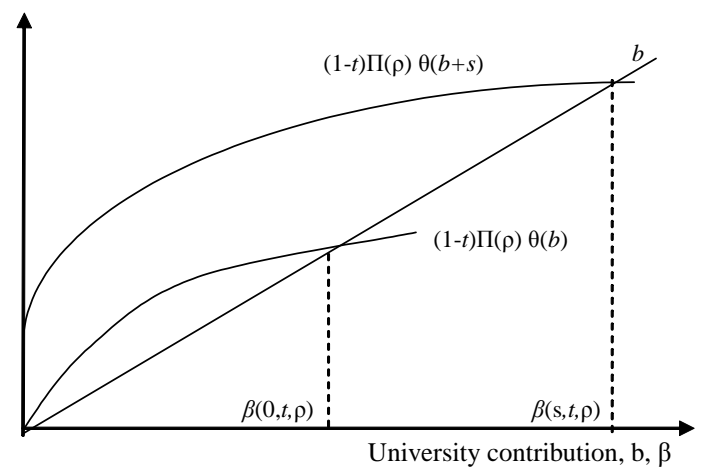

Figure 2: When $t$ is fixed, direct subsidies prime the pump

distinction will be of consequence because it affects the timing of the game between government sponsors and the university. If the levy is fixed as a primitive, it is not affected by subsidies. If the levy is endogenous, it can be adjusted to the subsidy according to the university's preferences. In section 5, where I consider matching subsidies, the research division's budget constraint is allowed to hold as an inequality (the Bayh-Dole profit after paying the university's research contribution can be positive), and the university's levy is positive residual.

Now consider how the university's spending on research responds to subsidies when the university's levy is fixed.

Figure 2 shows the university's spending when the direct subsidy is 0 and when the direct subsidy is some $s>0$, namely $\beta(0, t)$ and $\beta(s, t) . \beta(0, t)$ is described by the intersection of the curve $(1-t) \Pi(\rho) \theta(b)$ with the diagonal, and $\beta(s, t)$ is described by the intersection of $\Pi(\rho) \theta(b+s)$ with the diagonal. Assumption 1 ensures that the intersection in each case is at a positive level of spending.

Figure 2 shows that, provided the university's levy, $t$, is fixed, an increase in $s$ will cause the university's spending $\beta$ to increase. This answers the question whether subsidies crowd out university spending or increase it. When the levy is fixed, public subsidies "prime 
the pump." Subsidies have both a direct effect and indirect effect on idea generation. The indirect effect is that the subsidy leads to profitable ideas that feed more money into the university's budget, allowing the university to increase its spending on research even more.

However, as we will see below, "prime the pump" arises because the university chooses the levy rate before the sponsor makes its subsidy commitment. In the next section, the timing is reversed. The university chooses the levy after the subsidy has been set, and "prime the pump" disappears except when the university chooses a levy of 0 . Instead we will see crowding out.

\section{Proposition 1 .}

(a) [Priming the pump with direct subsidies] Given the levy t, an increase in the direct subsidy to the university, s, will cause total spending on research to increase by more than the increase in the subsidy. That is,

$$
\frac{\partial}{\partial s}[\beta(s, t)+s]=\frac{(1-t) \Pi(\rho) \theta^{\prime}(\beta(s, t)+s)}{1-(1-t) \Pi(\rho) \theta^{\prime}(\beta(s, t)+s)}+1>1
$$

(b) [Reducing spending by taxing it] Given the subsidy s, an increase in the levy $t$ will reduce university spending on research, that is,

$$
\frac{\partial}{\partial t} \beta(s, t)=\frac{-\Pi(\rho) \theta(\beta(s, t)+s)}{1-(1-t) \Pi(\rho) \theta^{\prime}(\beta(s, t)+s)}<0
$$

The proof consists of differentiating the budget constraint (5).

The intuition for "prime the pump" is simply that the subsidy results in ideas that can become profitable innovations, and the profit from the innovations is again fed into the idea-generating process.

Now consider the optimal subsidy policy. I assume that the sponsor's objective is to maximize (3), the consumer welfare provided through innovation. To accomplish that, the optimal innovation policy $\left(s, \rho^{*}\right)$ must satisfy

$$
s+\beta(s, t)=x^{*}
$$




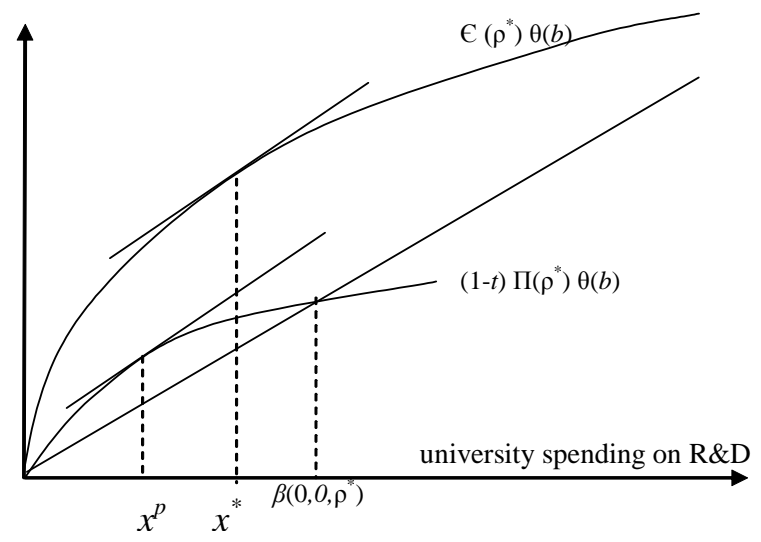

Figure 3: R\&D spending for maximum profit, maximum consumer welfare and budget exhaustion

However, figure 3 shows that the university might invest more in research than is consumer-optimal, even if the subsidy is zero. In figure 3, when the direct subsidy is $s=0$, the university spends $\beta(0, t)$, shown where $(1-t) \Pi(\rho) \theta(b)$ intersects the diagonal. The consumer-optimal level of $\mathrm{R} \& \mathrm{D}$ spending is shown as the value $x^{*}$ that satisfies (4). The profit maximizing level of expenditure is $x^{p}$ which satisfies

$$
x^{p}=\arg \max \left[\Pi\left(\rho^{*}\right) \theta(x)-x\right]
$$

It will hold that $x^{p}<x^{*}$ because $\Pi\left(\rho^{*}\right)<\epsilon\left(\rho^{*}\right)$. University spending $\beta(0, t)$ is larger than both $x^{*}$ and $x^{p}$ in figure 3 . This shows that, even without direct subsidies, developing ideas can be so profitable that the university overspends on generating ideas. This problem is worse when development is very lucrative, that is, $\Pi\left(\rho^{*}\right)$ is large, but is alleviated when the university imposes a high levy on Bayh-Dole profit. In the next section I consider the possibility that the university can change its levy.

\section{Subsidies that Crowd Out University Spending}

In the previous section, I assumed that the university's levy was fixed as an expression of the university's preferences, and that the sponsor's subsidy was chosen afterwards. I now 
reverse the timing. I assume that the subsidy is announced, and then the university chooses $t$ by maximizing a utility function. The subsidy considered in this section is a grant that is not contingent on the university's own contribution. In the next section, I compare with subsidies that are only available as matching grants to the university's contribution.

Because the Bayh-Dole act allows the university to profit from its research, the question arises whether the university will end up maximizing profit. The answer depends on how much value the university places on dollars diverted to the general fund, and how much value it places on research dollars.

To preview the results, if the university only values the general fund, it will want to maximize profit. The research division is viewed only as a money machine, and all the Bayh-Dole profits will be taxed away. On the other hand, if the university only values the dollars spent in research, then all profit will be returned to the research process in order to "prime the pump" for even more research. The total research spending will be greater than the level that maximizes profit, but this could be good for consumer welfare, since $x^{p}<x^{*}$.

If the university values both types of expenditure, but places more value on the general fund than on research spending, some of the profit will be taxed away, and the university will target a level of research spending that is larger than the profit-maximizing level. Because the university sets a target level of spending, subsidies will crowd out the use of BayhDole profits. Subsidies cannot increase R\&D spending unless the sponsor is already paying the entire research budget, so that further crowding out is not possible. Paying the entire research budget seems to defeat one of the benefits of the Bayh-Dole Act, namely, to make the university's research budget self-funding.

Let $m \geq 1$ be the value that the university places on each dollar of Bayh-Dole income that is diverted to the university's general fund, and suppose that dollars spent on research are valued at par. Thus $m$ expresses the university's preferences. With the preferences $m$ fixed and the subsidy $s$ already chosen by the government sponsor, the university chooses its levy on the Bayh-Dole profits, $t(s, m)$, to maximize its utility. In doing this, it predicts the effect of the levy on the research division's expenditures, according to the research division's 
budget constraint (5).

When the university contributes $b$ to research spending and the sponsor contributes $s$, the university also gets $\Pi(\rho) \theta(b+s)$, which I will call the Bayh-Dole profit. The subsidy $s$ must be spent on research, and the research division must not spend more than it takes in from subsidies and Bayh-Dole profits. This is implied by the budget constraint (5).

The university's objective function is

$$
\begin{aligned}
U^{m}(t ; s) & \equiv m t \Pi(\rho) \theta(b+s)+(1-t) \Pi(\rho) \theta(b+s)+s \\
& =[(m-1) t+1] \Pi(\rho) \theta(b+s)+s
\end{aligned}
$$

where $b$ is constrained by (5).

This objective function, like the objective function in section 4 , includes the research expenditure as a benefit as well as a cost. Research spending is a proxy for the amount of research that is done, which the university values. Because research expenditures count as a benefit, the university may target a higher level of research spending than is optimal for consumer welfare, and considerably higher than maximizes profit.

Let $t(s, m) \geq 0$ be the optimizer of the university's objective function, the optimal levy. The levy cannot be negative, that is, there cannot be "reverse" transfers from the general fund to the research budget. (For example, the university's core budget might come from tuition designated to support teaching or from funds designated for student-oriented programs.)

I first comment on two special cases, and then develop the general case. The two special cases are, first, that the university places equal weight on research spending and on the general fund $(m=1)$, and second, that the university sees the research enterprise only as a money machine, and does not value research for its own sake $(m \rightarrow \infty) .^{5}$

\footnotetext{
${ }^{5}$ I do not consider separately the possibility that $m<1$, because the university's choices are the same as when $m=1$. With $m=1$, the university would already like to transfer money from the general fund to the research budget, but I assume that is impossible. Such reverse transfers are even more tempting when $m<1$.
} 


\subsection{What if the university values research and the general fund equally?}

When $m=1$, the university's objective is simply to maximize profit $U^{1}=\Pi(\rho) \theta(\beta(s, t)+s)$ by choice of $t(s, 1)$. Given $s$, the university will choose the levy that results in the highest research spending $\beta(s, t)$. Since $\beta(s, t)$ decreases with the levy, it follows that $t(s, 1)=0$. The university will not tax the research enterprise at all. This implies, using Proposition 1(a), that government subsidies to R\&D again have the effect of priming the pump. Higher subsidies lead to an increase in R\&D spending that exceeds the increase in the subsidy. Spending is constrained only by the subsidy and the Bayh-Dole profits, and the university wants it to be as high as possible.

\subsection{What if the university does not value research?}

Suppose instead that the university only values the general fund. This will cause the university to maximize profit instead of $R \& D$ spending. Dividing the objective function $U^{m}$ by $m$, and letting $m \rightarrow \infty$, the university's objective becomes

$$
U^{\infty}(t ; s)=t \Pi(\rho) \theta(\beta(s, t)+s)
$$

Using the research division's budget constraint (5),

$$
\begin{aligned}
\Pi(\rho) \theta(b+s)-b & =t \Pi(\rho) \theta(b+s) \\
\Pi(\rho) \theta(\beta(s, t)+s)-\beta(s, t) & =t \Pi(\rho) \theta(\beta(s, t)+s)
\end{aligned}
$$

Maximizing the righthand side is the same as maximizing the lefthand side, and because $s$ is fixed, maximizing the lefthand side is the same as maximizing

$$
\Pi(\rho) \theta(\beta(s, t)+s)-[\beta(s, t)+s]
$$

If possible, the social planner will choose $t(s, \infty)$ such that profit is maximized, namely

$$
\beta(s, t(s, \infty))+s=x^{p} .
$$

If $s>x^{p}$, it is not possible to achieve the spending level $x^{p}$, because the university must spend the subsidy on research. However, the university will choose $t(s, \infty)=1$, and thus 
send all the remaining profit to the general fund. The subsidy is still greater than the level that maximizes profit.

However, if $s<x^{p}$, the university will choose the tax rate so that the $\mathrm{R} \& \mathrm{D}$ spending is topped up to the profit-maximizing level, $x^{p}$.

Notice that there will be "crowding out" when $s<x^{p}$. If the sponsor increases the subsidy (but still below $x^{p}$ ), the total spending on $\mathrm{R} \& \mathrm{D}$ will stay fixed at $x^{p}$. The university will decrease its own R\&D contribution to offset any increase in the subsidy. It will do this by increasing the levy $t(s, \infty)$ that diverts Bayh-Dole profits to the general fund. The subsidy crowds out the university's own spending. If the sponsor wants the university to spend more than $x^{p}$, it will have to pay the entire research budget, $s>x^{p}$.

\subsection{The general case}

Now consider the general case where $m \in(1, \infty)$. If $m>1$, the university gets more welfare from money diverted to the general fund than from money spent in research, but it values both uses of funds. As we saw in the two special cases, the university is caught between maximizing profit, which is the goal if it only values the general fund, and maximizing research expenditures, which is the goal if it only values research. These intermediate

preferences may cause the university to divert Bayh-Dole profit, similarly to the extreme case where $m \rightarrow \infty$. The university realizes that by diverting funds, it reduces the total amount of Bayh-Dole profit, because there is less "prime the pump" effect.

The sponsor sets the subsidy $s$, and then the university sets its levy, $t(s, m)$. The levy determines how much the university contributes to research from Bayh-Dole funds. It contributes $100 \%$ when $t(s, m)=0$ and nothing if $t(s, m)=1$. In setting the subsidy, the sponsor predicts the university's levy, which I will begin by describing. 
The derivative of the university's utility function $U^{m}$ is

$$
\begin{aligned}
\frac{d}{d t} U^{m}(t ; s) & =(m-1) \Pi \theta+[(m-1) t+1] \Pi \theta^{\prime} \beta_{t} \\
& =\frac{\Pi \theta}{\left[(1-t) \theta^{\prime} \Pi-1\right]}\left[(m-1)\left[(1-t) \Pi \theta^{\prime}-1\right]+[(m-1) t+1] \Pi \theta^{\prime}\right] \\
& =\frac{\Pi \theta}{\left[1-(1-t) \Pi \theta^{\prime}\right]}\left[m\left[\Pi \theta^{\prime}-1\right]+1\right]
\end{aligned}
$$

Recall that $\beta$ is the portion of Bayh-Dole funds returned to the research division, implied by the budget constraint (5). Its derivatives are given in Proposition 1 .

The first-order condition for the optimal $t(s, m)$ can be written

$$
\begin{array}{llll}
\geq 0 & \text { if } \quad t(s, m)=0 \\
=0 & \text { if } \quad t(s, m) \in(0,1) \\
\leq 0 & \text { if } \quad t(s, m)=1
\end{array}
$$

The value $x_{m}$ that satisfies (9) with equality will be called the university's target level of spending:

$$
\Pi(\rho) \theta^{\prime}\left(x_{m}\right)=1-\frac{1}{m}
$$

If there is a tax rate $t(s, m)$ such that $\beta(s, t(s, m))+s=x_{m}$, this is the level of spending it will choose.

For all $m>1$, the target $x_{m}$ is larger than the level of spending that maximizes profit (Proposition 2(a)). Intuitively, this is because research expenditures are valued as a benefit as well as a cost - they are a proxy for research outputs. As we have seen, if the university did not value research expenditures at all, it would target the profit-maximizing level of research expenditure, and divert all additional profits to the general fund.

The university cannot always achieve the target. If $s$ is very low, so that $s+\beta(s, 0)<x_{m}$, the university has less budget available than $x_{m}$ (Proposition 3(a)). Moreover, if the subsidy is higher than the target and if (as I assume) the university cannot divert the subsidy itself to other uses, the university will have to spend more than the target. All Bayh-Dole profits will be crowded out, that is, diverted to other uses, which means $t(s, m)=1$ (Proposition 2(c) and Proposition 3(c)). This will turn out to be a good thing, not a bad thing, because 
it enables the sponsor to increase spending above the university's target, which could be too low.

Say that it is feasible to achieve the target $x_{m}$ with a subsidy $s$ if $s \leq x_{m}$ and $s+\beta(s, 0)>$ $x_{m}$. As I have just pointed out, if the subsidy were higher than the target, the university would have to spend more than the target. The condition $s+\beta(s, 0)>x_{m}$ implies that there is enough Bay-Dole profit to fill the gap between the subsidy and the target. In particular, there is a tax rate $t(s, m)$ such that $s+\beta(s, t(s, m))=x_{m}$. This is Proposition 2(b). The higher subsidy crowds out Bayh-Dole profits without increasing the level of spending above $x_{m}$. When the subsidy increases, the levy increases to hold the rate of spending fixed at the target.

Proposition 2 describes how the university's total spending responds to the subsidy, and the levels of spending that can be achieved. Proposition 3 restates these conclusions in terms of the levy that the university will charge.

\section{Proposition 2 (The university's target level of spending, and crowding out) . (a)}

The university's target level of spending satisfies $x_{m}>x^{p}$, decreases with $m$ and converges to $x^{p}$ as $m \rightarrow \infty$.

(b) [Crowding Out] If it is feasible to achieve the target $x_{m}$ with the subsidy s, the university spends $x_{m}$ and fill the gap between $s$ and $x_{m}$ with Bayh-Dole profits. A higher subsidy crowds out Bayh-Dole profits one-for-one.

(c) [Full crowding Out] Given $m$ if $s>x_{m}$, the university spends $s$, and $t(s, m)=1$. All the Bayh-Dole profits are crowded out.

(d) For any $x<\min \left\{\beta(0,0), x_{m}\right\}$ there is no subsidy such that the university will spend $x$.

(e) For any $x \geq \min \left\{\beta(0,0), x_{m}\right\}$ there is a subsidy such that the university will spend $x$.

Proof: (a) It follows from concavity of $\theta$ that $x_{m}$ decreases with $m$. Profit $\Pi(\rho) \theta(x)-x$ is maximized when $\Pi(\rho) \theta^{\prime}\left(x^{p}\right)-1=0$ Because $\theta^{\prime}$ is decreasing, it follows that $x_{m}>x^{p}$. Further, as $m \rightarrow \infty$, the two first order conditions coincide, so $x_{m} \rightarrow x^{p}$.

(b) If the subsidy $s$ is less than the target $x_{m}$, then according to (8) and (9), the university will fill the gap with Bayh-Dole profits: $x_{m}=\beta(s, t(s, m))+s=(1-t(s, m)) \Pi(\rho) \theta\left(x_{m}\right)+$ 
$s$, so $x_{m}-s=(1-t(s, m)) \Pi(\rho) \theta\left(x_{m}\right)$.

(c) Because the university's profit function is strictly concave, the objective function has a higher value if the level of spending is moved closer to the target. If $\beta(s, t(s, m))>0$, the university is spending $s+\beta(s, t(s, m))$. The spending is closer to the target $x_{m}$ if $\beta(s, t(s, m))=0$, which entails choosing $t(s, m)=1$.

(d) With no subsidy and keeping all the Bayh-Dole Profit, the university does not have enough money to reach the target.

Proposition 3 restates these results in terms of the optimal levy, as the levy depends on the subsidy.

\section{Proposition 3 (The optimal levy) .}

(a) Given $m$, if $s+\beta(s, 0)<x_{m}$, the university's optimal levy satisfies $t(s, m)=0$, all Bayh-Dole profits are used for research, and the university's RED spending falls short of the target.

(b) For subsidies $s$ such that it is feasible to reach the target $x_{m}$, the university's levy satisfies $t(s, m) \in(0,1)$, so that part of the research is paid for by Bayh-Dole profits, and the university spends $x_{m}$ on research.

(c) For subsidies $s>x_{m}$, the university's levy satisfies $t(s, m)=1$, the university spends $s$ in research, and none of the research budget is paid for from Bayh-Dole funds.

The important implication of Proposition 3 is that, if the sponsor wants to achieve the consumer-optimal level of spending $x^{*}$, there are three possibilities:

1. The university wants to spend more than the sponsor wants to spend, and can generate at least enough Bayh-Dole profit to reach the sponsor's target. That is, $x^{*}<\min \left\{x_{m}, \beta(0,0)\right\}$. Then there is no point in providing subsidies. Spending will be higher than the sponsor prefers in any case, and will be funded from Bayh-Dole profits. There is no way to reduce spending.

2. The university wants to spend more than the sponsor wants to spend, but cannot generate enough funds to reach the sponsor's target $x^{*}$. That is, $\beta(0,0)<x^{*} \leq x_{m}$. 
Then the sponsor will provide a subsidy $s$ that satisfies $\beta(s, t(s, m))+s=x^{*}$ and $t(s, m)=0$.

3. The university wants to spend less than the sponsor wants to spend, that is, $x_{m}<x^{*}$. Regardless of how much Bayh-Dole profit is available, the sponsor must fund the entire research budget, $x^{*}$. The Bayh-Dole profits are crowded out. If the subsidy were less than $x_{m}$, the university would spend enough Bayh-Dole profits to reach $x_{m}$, but not more. For any subsidy greater than $x_{m}$, the university will not spend any Bayh-Dole profits on research.

Thus,

Proposition 4 (Crowding Out) Suppose the university can adjust its internal levy according to the subsidy provided. Despite crowding out, the sponsor can increase research spending in two circumstances: (1) if the university wants more spending than the sponsor wants, but Bayh-Dole profits are not large enough to fund the sponsor's target, and (2) if the sponsor wants more spending than the university wants. In the case (1), the sponsor can reach its target with no crowding out. The research is funded jointly from Bayh-Dole funds and subsidies. In the case (2), the sponsor can reach its target, but with complete crowding out. The subsidy must fund the entire research budget.

Of the two possibilities, the second might be the more likely, since the sponsor will typically want to achieve the consumer-optimal level of spending $x^{*}$.

\section{$5 \quad$ Matching Subsidies}

So far I have supposed that the university can impose a levy on Bayh-Dole profits, and I have considered the optimal subsidy policies in the two cases that the university can or cannot change its levy to reflect the subsidy. In both cases, the university might overspend on research, relative to the spending level that maximizes consumer welfare, and in the second case, there is a problem of crowding out. 
I now suppose that the sponsor can protect itself from crowding out by making the subsidy contingent on matching. Matching mitigates the problem of crowding-out by definition, since a specified portion of the research budget must be paid by the university. Although matching is generally not imposed by the U.S. federal government or by grant-giving foundations, it often occurs when profit-maximizing firms sponsor university research in return for intellectual property rights and control rights. For that situation, Maurer and Scotchmer (2004) (see also Scotchmer 2004, Ch. 8) concluded that matching can lead to better selection of projects. In this paper, however, the sponsor will not receive the intellectual property and does not want the control rights. Matching will therefore serve a different purpose, in particular, to avoid crowding out.

Let the sponsor's matching rate be $\gamma \geq 0$. The sponsor will provide matching funds $s=\gamma b$ when the university provides research funds $b$. To get a large subsidy, the university must commit a lot of its own funds. The university then spends $s+b=b(1+\gamma)$ on research, and earns profit Bayh-Dole profit $\Pi(\rho) \theta(b(1+\gamma))$. The university can either use the Bayh-Dole profit for research or divert it to the general fund. The amount that is diverted to the general fund is $\Pi(\rho) \theta(b(1+\gamma))-b$. Thus, the university's levy is modeled implicitly according to the portion of Bayh-Dole profits that are not used for research.

The objective function of the university is to maximize

$$
\begin{aligned}
\bar{U}^{m}(b ; \gamma) & \equiv m[\Pi(\rho) \theta(b(1+\gamma))-b]+(1+\gamma) b \\
& =m \Pi(\rho) \theta(b(1+\gamma))+(1+\gamma-m) b
\end{aligned}
$$

subject to

$$
\Pi(\rho) \theta(b(1+\gamma))-b \geq 0
$$

The maximum possible Bayh-Dole profit is the $b$ that satisfies (11) with equality. I will use $\bar{\beta}(\gamma)$ for the solution to (11) as an equality. When the constraint holds as an inequality, the university is making less profit than would be possible if it gave all the profit back to research, and is also diverting some of the profit to other uses. Compare with (5), which holds as an equality. The levy of the university is modeled explicitly as a tax. 
By Assumption 1, the profit surplus $\Pi(\rho) \theta(b(1+\gamma))-b$ is positive for $b$ near zero, decreasing with $b$, and negative for large enough $b$, similarly to what is shown in figure 3 . (Figure 3 is not drawn for the case of matching funds, so there is no $\gamma$.)

Now let $b^{m}(\gamma)$ be the unconstrained maximizer of $(10)$, and take $b^{m}(\gamma)(1+\gamma)$ as the university's target for research spending. If the inequality (11) is satisfied at $b^{m}(\gamma)$, the university will spend $b^{m}(\gamma)$. Otherwise, the university will be constrained by the maximum Bayh-Dole profit, $\beta(\gamma)$, and its actual spending will be less than the target, $b^{m}(\gamma)(1+\gamma)$.

Thus, the university's spending on research is $(1+\gamma) \min \left\{b^{m}(\gamma), \bar{\beta}(\gamma)\right\}$.

Several aspects of the university's R\&D decision are apparent simply by inspecting its objective function.

First, the mere fact of matching mitigates the problem of crowding out. The university pays a share $1 /(1+\gamma)$.

Second, matching funds can be so attractive that the university spends the entire budget on research, including both Bayh-Dole profit and the subsidy. If $1+\gamma-m>0$, then the derivative of $\bar{U}^{m}$ with respect to $b$ is positive for all $b$, and the university will spend all the Bayh-Dole profit, $\bar{\beta}(\gamma)$, on research. Conditional on $\gamma$, total spending is thus $\bar{\beta}(\gamma)(1+\gamma)$. If $1+\gamma-m<0$, the university might choose a target less than $\bar{\beta}(\gamma)(1+\gamma)$, and to achieve it, might divert some of its Bayh-Dole profit to the general fund.

Third, as in section 4, there is a natural reason that the university might overspend on R\&D, even without subsidies. The university gets two types of benefit from spending on R\&D. Not only is the university rewarded with Bayh-Dole profit, but it also gets utility from the research expenditures directly. Research expenditures are a proxy for the fame that comes with research outputs. These two benefits of $R \& D$ spending show up in the objective function $\bar{U}^{m}$, where the cost term, $-b$, is offset by the term that reflects the benefits of spending on research, and thus vanishes completely when $m=1$.

Proposition 5 now describes how the total spending on R\&D depends on the matching rate $\gamma$, and therefore describes how the sponsor can influence total R\&D spending. The university's "target" now changes with $\gamma$ as well as $m$. Compare with the previous section, 
where the target depended only on the preference parameter $m$.

Taking the derivative of $\bar{U}^{m}$, the university's unconstrained research target $b^{m}(\gamma)$ is described by

$$
\begin{gathered}
\frac{d}{d b} \bar{U}^{m}\left(b^{m}(\gamma) ; \gamma\right)=m\left[\Pi(\rho) \theta^{\prime}\left(b^{m}(\gamma)(1+\gamma)\right)(1+\gamma)-1\right]+(1+\gamma) \\
=0 \quad \text { if } \quad b^{m}(\gamma)<\infty \\
\frac{d}{d b} \bar{U}^{m}\left(b^{m}(\gamma) ; \gamma\right) \quad \text { if } \quad b^{m}(\gamma)=\infty
\end{gathered}
$$

The target $b^{m}(\gamma)=\infty$ is obviously unachievable. The university would like to spend infinite resources on research when $m<(1+\gamma)$ because the derivative (13) is positive for all values of $b$. However, spending is constrained by the budget constraint (11), which describes the maximum Bayh-Dole profits, $\bar{\beta}(\gamma)$. When $m$ is relatively low, the university does not place very much weight on diverting profit to the general fund, and keeping the profits within the research budget has a "prime the pump" effect.

If $m>(1+\gamma)$, the target $b^{m}(\gamma)$ might or might not exceed the Bayh-Dole profits given by (11). If not, some of the university's research income will be diverted to the general fund. Research spending will stop at the point where the university's valuation of an extra dollar in research (accounting for the fact that it attracts matching funds and then generates income) is just equal to the university's valuation of that dollar placed in the general fund.

Proposition 5 characterizes how the sponsor can use the matching rate to govern the university's rate of spending.

\section{Proposition 5 (The university's R\&D spending with matching) .}

(a) Let $x<\min \left\{b^{m}(0), \bar{\beta}(0)\right\}$. Then there is no $\gamma \geq 0$ such that the university spends $x$ in research.

(b) Let $x>\min \left\{b^{m}(0), \bar{\beta}(0)\right\}$. Then there exists $\gamma \geq 0$ such that the university spends $x$ and the cost is funded partly out of Bayh-Dole profits.

(c) For all $\gamma \geq 0$ and $m \geq 1$, the university's spending $(1+\gamma) \min \left\{b^{m}(\gamma), \bar{\beta}(\gamma)\right\}$ exceeds the profit maximizing level, $x^{p}$, but decreases with $m$ and converges to $x^{p}$ as $m \rightarrow \infty$.

(d) When $m \leq 1+\gamma$, the university spends all its Bayh-Dole profit on research, namely, 
$\bar{\beta}(\gamma)$. If $m>1+\gamma$, the university may divert some of the Bayh-Dole profit to the general fund.

Proof: (a) Both $(1+\gamma) b^{m}(\gamma)$ and $(1+\gamma) \bar{\beta}(\gamma)$ are increasing in $\gamma$, and therefore $x<$ $\min \left\{b^{m}(0), \bar{\beta}(0)\right\}<(1+\gamma) \min \left\{b^{m}(\gamma), \bar{\beta}(\gamma)\right\}$. This means that at any matching rate $\gamma$, the university is both able and willing to spend more than $x$. (b) For sufficiently large $\gamma$, $m<1+\gamma$, and the derivative of $\bar{U}^{m}$ is positive for all levels of spending. The univesity will spend as much resources as in research as are available, and therefore the university's spending will be entirely determined by its Bayh-Dole profits. The Bayh-Dole profits can be made arbitrarily large by choosing $\gamma$ arbitrarily large.

(c) The profit maximizing value $x^{p}$ and the target $b^{m}(\gamma)(1+\gamma)$ satisfy the following respectively

$$
\begin{aligned}
\Pi(\rho) \theta^{\prime}\left(x^{p}\right)-1 & =0 \\
\Pi(\rho) \theta^{\prime}\left(b^{m}(\gamma)(1+\gamma)\right)-1+\frac{(1+\gamma)}{m} & \geq 0 \text { with equality if } b^{m}(\gamma)<\infty
\end{aligned}
$$

Due to concavity of $\theta$, these two first-order conditions imply that $b^{m}(\gamma)(1+\gamma)>x^{p}$ for $\gamma \geq 0$. However, as $m \rightarrow \infty$, the two first-order conditions in (14) coincide. Since the objective functions are strictly concave, and there is a single level of spending where the first-order condition is satisfied, this proves that $b^{m}(\gamma)(1+\gamma) \rightarrow x^{p}$ for each $\gamma$ Finally, to see that the expenditure is nonincreasing with $m$, it is enough to show that $b^{m}(\gamma)$ is nonincreasing with $m$. But this also follows from (13).

(d) I argued in (b) that when $m \leq 1+\gamma$, the university will spend as much as it has available from Bayh-Dole profits. I argued in (c) that for large $m, b^{m}(\gamma)(1+\gamma)$ is close to $x^{p}$, the profit-maximizing level of spending. But at $x^{p}$, there is positive profit not used in research, $\Pi(\rho) \theta\left(b^{m}(\gamma)(1+\gamma)\right)-b^{m}(\gamma)(1+\gamma)>0$, so some of the Bayh-Dole profit is available for the general fund.

I now compare matching to the noncontingent subsidies of the last section. Is matching a better subsidy scheme? First, can it correct inefficiencies that might arise with noncon- 
tingent subsidies? Second, can it reduce the degree to which Bayh-Dole profits are diverted to uses other than R\&D spending? These are answered in the following proposition, which says that the schemes are equivalent in the levels of research spending they can achieve, but matching can increase the use of Bayh-Dole profits for research.

For a given spending level $x$, say that the sponsor can achieve $x$ if there is a noncontingent subsidy, $s$, or matching rate, $\gamma$, respectively, that induces the university to spend $x$ in research. I consider all values of $x$ for completeness. The $x$ that maximizes consumer welfare can be larger or smaller than the university's target. Any $x$ above the target can be achieved in both regimes, but will not be funded out of Bayh-Dole profits in the noncontingent-subsidy regime. In this sense, the matching scheme is an improvement. ${ }^{6}$

Proposition 6 [Matching versus Noncontingent Subsidies] The same spending levels in the university can be achieved with both noncontingent subsidies and with matching subsidies. However, for large spending levels, the matching system has the added benefit that part of the spending is funded from Bayh-Dole profits.

Proof: For the case of noncontingent subsidies, Proposition 2 says that every level of spending $x$ can be implemented except $x<\min \left\{\beta(0,0), x_{m}\right\}$. For the case of matching, Proposition 5 says that every level of spending $x$ can be achieved except $x<\min \left\{\bar{\beta}(0), b^{m}(0)\right\}$. But it follows from the budget constraints (5) and (11) that $\beta(0,0)=\bar{\beta}(0)$ and and it follows from the first order conditions (8) and (13) that $x_{m}=b^{m}(0)$. Hence, these are equivalent.

\section{Should ideas be protectable?}

Now suppose that ideas go into the public domain instead of being protected. There is a longstanding theory, originating with Nelson (1959) and Arrow (1962) that because R\&D

\footnotetext{
${ }^{6}$ It might also be an improvement in another sense, if it is costly to raise public funds, that is, if $k>1$ in the sense of footnote 4. Bayh-Dole profits will be collected regardless of how they are spent, and a reduction in funds from the general fund reduces the waste of collecting those funds. Of course this is a very partialequilibrium argument. It might not apply if total spending in the university is the same in both regimes, with the sponsored portion simply shifting between the research division and the general fund.
} 
produces knowledge, and because knowledge is a public good, it should be produced with public funds and made freely available. Although that theory was apparently rejected by the framers of the Bayh-Dole Act, it still seems persuasive. I now investigate whether consumer welfare would be higher in this model by embracing that theory.

Many ideas $(v, c)$ will have value $v / r$ much greater than the costs $c$ of implementing them. If such ideas were freely available, they would engender patent races. In contrast, when ideas are protectable, patent races are avoided by auctioning exclusive licenses. Patent races are inefficient in this model because they entail duplicated costs. ${ }^{7}$ To avoid inefficient patent races, the reward should be reduced, by reducing the parameter $\rho$. However, reducing the profit available from commercialization has the deleterious effect of eliminating some ideas that should optimally be commercialized.

When ideas are not protectable, consumer welfare is given by the following, where $(1 / r) \Pi(\rho)$ is subtracted from consumer welfare because firms in a race will dissipate the entire profit. This is a waste of resources in expected amount $(1 / r) \Pi(\rho)$.

$$
\begin{aligned}
W^{u}(x, \rho) & =\frac{1}{r}[\theta(x)(\epsilon(\rho)-\Pi(\rho))-x] \\
& =W(x, \rho)-\frac{1}{r} \theta(x) \Pi(\rho)
\end{aligned}
$$

Because $W^{u}(x, \rho)<W(x, \rho)$ for any $(x, \rho)$, consumer welfare would be higher with protection of ideas than without protection if the same values of $(x, \rho)$ could be implemented in both regimes. However, that is not the case. The university is earning Bayh-Dole profits when ideas are protected, but not otherwise. Thus, the spending levels $x$ that are implemented by a policy $(s, \rho)$ will be different.

When ideas are not protected, the set of implementable spending levels is just the set

\footnotetext{
${ }^{7} \mathrm{~A}$ complexity of $\mathrm{R} \& \mathrm{D}$ is that the economy comprises different innovative environments. The core model of the $R \& D$ literature is that investment opportunities are common knowledge, and that is what leads to racing. I have always thought that premise to be flawed, and in my 1999 paper, began to work on a model, extended here, where investment opportunities (ideas) are scarce. Because they are not common knowledge , inefficient races are not a threat unless there is some mechanism by which the ideas become common knowledge.
} 
of possible subsidies, which I will $\mathcal{X}^{u}$ :

$$
\mathcal{X}^{u}=R_{+}
$$

I do not need to consider the matching regime separately from the regime with noncontingent subsidies, since the set of implementable spending levels is the same. However, I consider that the university's levy could be set before the subsidy or

after.The spending levels that can be implemented by policies $(s, \rho)$ depend on $\rho$, since the research division partly spends money earned through commercialization. I will refer to these sets as $\mathcal{X}^{t}(\rho)$ and $\mathcal{X}^{\tau}(\rho)$ :

$$
\begin{aligned}
& \mathcal{X}^{t}(\rho)=\left\{x \in R_{+}: x \geq \beta(0, t)\right\} \\
& \mathcal{X}^{\tau}(\rho)=\left\{x \in R_{+}: x \geq \max \left\{x_{m}, \beta(0,0)\right\}\right\}
\end{aligned}
$$

where the taste parameter is $m$, and $x_{m}$ is the target level of spending. The sets do not refer to $s$, because the expenditures that can be implemented by all $s$ are already included in the sets as written. For example, in $\mathcal{X}^{t}(\rho)$, if $s>0$, then $x=s+\beta(s, t)$, which is larger than $\beta(0, t)$, and also in the set $\mathcal{X}^{t}(\rho)$.

The only reason that protecting ideas might reduce welfare is that such protection could generate too much spending on the generation of ideas. The spending rates that are implementable are bounded below, due to the profitability of commercializing the ideas. However, overspending is not generally understood as the main problem, especially when the university can tax away the profit from commercializations.

The following remark says in essence that as long as overspending is not a problem, it is better to protect ideas than not to protect them.

Remark 1 (Protection of ideas as well as commercializations can be welfare enhancing) Suppose that $(\hat{x}, \hat{\rho})$ maximizes $W^{u}$ and $\left(x^{*}, \rho^{*}\right)$ maximizes $W$. Provided $\hat{x} \in \mathcal{X}^{t}(\hat{\rho})$ and $\hat{x} \in \mathcal{X}^{\sim} t(\hat{\rho})$, then $W\left(x^{*}, \rho^{*}\right)>W^{u}(\hat{x}, \hat{\rho})$. It is better for consumer welfare to protect ideas than not. 


\section{Some reflections on basic and applied research}

The model in this paper contemplates that there are two research processes: a process that turns up ideas or knowledge, and the innovation process that turns ideas into innovations. The model turns up only an ambiguous reason for putting ideas in the public domain, namely, to encourage patent races in the case that patent races are efficient. However, patent races might or might not be efficient, and in this model, they are not.

Because the commercialization of each idea is protected, ideas are profitable. Why then does the ideas process need to be subsidized? The answer given above is that a pure profit motive, such as one would expect from private firms and might even arise in the university, will lead to underinvestment, which subsidies can cure.

It is tempting to interpret the ideas process in this model as "basic research". However, there are no agreed-upon definitions of basic and applied research. The model here bears little resemblance to the definition given, for example, by Nelson (1959), and expanded by Pavitt (1990). Nelson defined basic research by its characteristics, perhaps most importantly, the degree to which the new knowledge can be appropriated. If basic research has social value but no commercial value (that is, the social value cannot be appropriated), then it is a short leap to the conclusion that basic research must be subsidized, and might naturally take place in universities or public laboratories with grant support.

On closer inspection, the profit distinction between basic and applied research is shaky. When a laboratory finds a drug target (but not the drug), is that basic research? If the

drug target is patentable, it has commercial value. Similarly, ideas in the above model have commercial value if they are protected, but not otherwise. The commercial value is not intrinsic to the technology, but rather to the legal rule. Appropriability cannot be used as a definition of basic research because appropriability is a status of law, not a status of the technology.

For this reason, I put appropriability aside, and turn to a second characteristic emphasized by Nelson, namely, whether the new knowledge is an input to the creation of further knowledge. Such inputs might usefully be called "research tools", although that term is 
sometimes understood more narrowly than here. For my purposes, the knowledge that will lead to future knowledge or products might or might not have a physical embodiment. It might be a machine with multiple purposes, or it might be disembodied knowledge such as how the body regulates division of cells. As a policy matter (and even in current legal rules) both could be patentable.

I now comment on how the subsidy problem changes if universities are mainly in the business of finding research tools, which are then licensed to commercial firms to develop ideas not observed by the university/owner. In the model above, the ideas (investment opportunities) generated by the university are observable to the university. In the case of research tools, I assume the research tools generate investment opportunities, but the investment opportunities (ideas) are not observable to the university. This lack of observability reduces the commercial profit that the university can collect, and also stifles development of some ideas that would otherwise be profitable. For example, if the license involves fixed fees or royalties tied to the revenue stream, there will be some ideas with cost smaller than total profit that will be lost because the licensor is collecting too much of the revenue, and the developer cannot cover costs. The idea might not be developed even if it would generate positive profit in total.

Thus, observability of the ideas determines how effectively the research division can profit from commercialization. If the investment ideas are known to the university and protected, they can be auctioned to developers. There is still a social burden due to monopoly pricing of the commercializations, but there is no additional burden of inhibiting development by charging royalties. If an idea is not very profitable, it will still be developed, but the winning bidder will not pay much for it.

In contrast, when the ideas are not observable to the licensor, the university cannot auction them, the license terms cannot be tied to the cost of development, and in trying to collect profit, the licensor will impose terms that also stifle development of some ideas. This is an argument for subsidizing the research tools and putting them in the public domain so that the users do not need to license. 


\section{Conclusion}

Although the rationale for the Bayh-Dole Act was not to make university research selffunding, administrators had such hopes, and many universities created licensing offices to harvest the profit. However, I have argued that, due to crowding out, the Bayh-Dole profit might not relieve fiscal pressure on the sponsors of research. Much of the profit could be diverted to other activities.

I have assumed that universities and sponsors have different objectives. Universities care about profits, but also care about research outputs, independently of the profit they generate. Because universities value research for its own sake, they will target a higher level of spending than maximizes profit, but perhaps less than is optimal from a consumerwelfare point of view in the economy as a whole. I have assumed that sponsors of research care about consumer welfare, and subsidizing the university is a vehicle to increase research spending. Although the university's spending target is higher than maximizes profit, the target might still be lower or higher than is efficient. If the target is already too high, there is nothing the sponsor can do to reduce it. If the target is too low, the sponsor can increase spending on research by giving subsidies, but up until the point where the subsidy exceeds the target, the subsidy will only crowd out the use of Bayh-Dole profits while maintaining a spending level equal to the university's target. In order to increase spending above the target, the sponsor must pay the entire research bill. Bayh-Dole funds will be used for something else.

Crowding out occurs because the university adjusts its internal levy on Bayh-Dole profits - the more subsidy, the more tax. I also explored two aspects that mitigate the crowding out. If university's internal levy on Bayh-Dole profits cannot be adjusted according to the subsidy, then subsidies "prime the pump." R\&D spending increases not only because of the direct effect of the subsidy, but also because of the indirect effect. The subsidy feeds ideas that generate even more profit. Of course, since the levy is presumably informal, there is no way for the sponsor to insist that it stay fixed.

The other possibility is for the subsidies to be given on a matching basis. By defini- 
tion, the university and sponsor share the research budget in fixed proportions, so there is crowding out. To the best of my knowledge, the federal government does not give funds on this basis, although private firms have been known to give funds on this basis.

Unlike other theoretical models of Bayh-Dole incentives, the model in this paper is focussed on institutional incentives rather than on the incentives of the individual researchers. The model leaves aside another question of interest, which is whether the profit opportunities created by the Bayh-Dole Act divert researchers from more important pursuits. That question does not arise in my model. Instead, this paper is concerned with the level of spending on investment opportunities (ideas), and whether Bayh-Dole profit has the effect of topping up research budgets to increase total spending.

The key assumption is that the university has an incentive to tax the profits from commercialization according to its preferences. This can nullify an apparent benefit of the Bayh-Dole Act, namely, to create a source of research funds. Due to crowding out, the subsidies required to support research might be as high as when ideas are not patentable, and the profits from commercialization will simply feed the university more generally.

\section{References}

[1] Aghion, P., M. Dewatripont and J. C. Stein. 2008. "Academic freedom, private-sector focus, and the process of innovation." RAND Journal of Economics 39:617-635.

[2] Arrow, K. 1962. "Economic Welfare and the Allocation of Resources for Invention." In R. Nelson, ed., The Rate and Direction of Economic Activities: Economic and Social Factors, 609-626. National Bureau of Economic Research Conference Series. Princeton, NJ: Princeton University Press.

[3] Azoulay, P., Waverly, D., Toby, S., 2009. The impact of academic patenting on the rate, quality, and direction of (public) research output. Journal of Industrial Economics 57, $637-676$. 
[4] Banal-Estañol, A. and I. Macho-Stadler. 2010. "Scientific and Commercial Incentives in R\&D: Research versus Development?" Journal of Economics and Management Strategy 19:185-221.

[5] Bilski v. Kappos, 130 S. Ct. 3218 - Supreme Court 2010

[6] Boettiger, Sara and Alan Bennett. 2006. Bayh-Dole: if we knew then what we know now. Nature 24: 320-323.

[7] Erkal, N. and S. Scotchmer. 2007. "Scarcity of Ideas and Options to Invest in R\&D," University of California, Berkeley, Department of Economics, Working Paper 07-348.

[8] Erkal, N. and S. Scotchmer. 2009. "Scarcity of Ideas and R\&D Options: Use it, Lose it or Bank it," NBER Working Paper No. 14940.

[9] Gans, J. S. and F. Murray. 2010. "Funding Conditions, the Public-Private Portfolio and the Disclosure of Scientific Knowledge." National Bureau of Economic Research conference paper, Rate and Direction of Inventive Activity.

[10] Grimaldia, Rosa, Martin Kenney, Donald S. Siegeld, Mike Wrighte. 2011. 30 years after Bayh-Dole: Reassessing academic entrepreneurship. Research Policy 40:1045- 1057.

[11] Henderson, R., Jaffe, A., Trajtenberg, M., 1998. Universities as a source of commercial technology: A detailed analysis of university patenting, 1965-1988. Review of Economics and Statistics 80 (1), 119-127

[12] Jensen, R., J. Thursby and M. C. Thursby. 2010. University-Industry Spillovers, government Funding, and Industrial Consulting. National Bureau of Economic Research Working paper 15732 .

[13] Lach, Saul and Mark Schankerman. 2008. "Incentives and invention in universities." The RAND Journal of Economics 39(2), 403-433. 
[14] Maurer, S. M. and S. Scotchmer. 2004. "Procuring Knowledge." In Libecap, G., ed., Intellectual Property and Entrepreneurship: Advances in the Study of Entrepreneurship, Innovation and Growth, Vol 15, pp. 1-31. The Netherlands: JAI Press (Elsevier).

[15] Mowery, David C., Richard R. Nelson, Bhaven N. Sampat, and Arvids A. Ziedonis. 2004. Ivory Tower and industrial Innovation: University-Industry Technology Transfer before and after the Bayh-Dole Act. Stanford, CA: Stanford University Press.

[16] Mowery, David C., and Arvids A. Ziedonis. 2002. Academic patent quality and quantity before and after the Bayh-Dole act in the United States. Research Policy 31:399-418

[17] Mazzolini, Roberto. 2005. University patents, R\&D competition, and social welfare. Economics of Innovation and New Technology 14(6): 499-515.

[18] Nelson, R. 1959. "The simple economcis of basic scientific research." Journal of Political Economy 67:297-306.

[19] Nordhaus, W. 1969. Invention, Growth and Welfare: A Theoretical Treatment of Technological Change. Cambridge, MA: MIT Press.

[20] O'Donoghue, T., Scotchmer, S. and Thisse, J.-F. 1998. "Patent Breadth, Patent Life and the Pace of Technological Progress," Journal of Economics and Management Strategy, 7, 1-32.

[21] Pavitt, Keith. 1990. What makes basic research economically useful? Research Policy 20:109-119.

[22] Rafferty, Matthew. 2008. The Bayh-Dole Act and university research and development. Research Policy 37:29-40.

[23] Sampat, Bhaven N., David C. Mowery and Arvids A. Ziedonis. 2003. Changes in university patent quality after the Bayh-Dole act: a re-examination. The economics of intellectual property at universities, 21(9):1371-1390. 
[24] Scotchmer, S. 1999. "On the Optimality of the Patent Renewal System," RAND Journal of Economics, 30, 131-196.

[25] Scotchmer, S. 2004. Innovation and Incentives. Cambridge, MA: MIT Press.

[26] Stern, S. 2004. "Do scientists pay to be scientists?" Management Science 50:835-853. 
[27] Thursby, Jerry G. and Marie C. Thursby. 2011. Has the Bayh-Dole act compromised basic research? Research Policy 40:1077-1083.

[28] Thursby, M., Thursby, J., Swasti, G.-M., 2007. Are there real effects of licensing on academic research? A life-cycle view. Journal of Economic Behavior 85 Organization $63,577-598$.

[29] Thursby, Jerry G. and Thursby, Marie C. "Policy Forum: University Licensing and the Bayh-Dole Act". 22 August 2003. Science 301 (5636): p. 1052. DOI: 10.1126/science. 1087473 